\title{
The immunogenetics of multiple sclerosis. The frequency of HLA-alleles class 1 and 2 is lower in Southern Brazil than in the European population
}

\author{
Imunogenética na esclerose múltipla. A frequência dos alelos HLA classe 1 e 2 no sul do \\ Brasil são menores que da população Europeia \\ Lineu Cesar Werneck', Paulo José Lorenzoni', Raquel Cristina Arndt', Cláudia Suemi Kamoi Kay?, \\ Rosana Herminia Scola ${ }^{1}$
}

\begin{abstract}
Objective: To study the HLA of class 1 and 2 in a multiple sclerosis (MS) population to verify the susceptibility for the disease in the Southern Brazil. Methods: We analyzed patients with MS and controls, by direct sequencing of the genes related to HLA DRB1, DQB1, DPB1, A, B and C alleles with high resolution techniques. Results: We found a lower frequency of all HLA alleles class 1 and 2 in MS and controls comparing to the European population. Several alleles had statistical correlation, but after Bonferroni correction, the only allele with significance was the HLA-DQB1*02:03, which has a positive association with MS. Conclusions: Our data have different frequency of HLA-alleles than the previous published papers in the Southeast Brazil and European population, possible due to several ethnic backgrounds.
\end{abstract}

Keywords: genetic predisposition to disease; HLA antigens; immunogenetics; major histocompatibility complex; multiple sclerosis.

\section{RESUMO}

Objetivo: Estudo do HLA classes 1 e 2 em pacientes com esclerose múltipla (EM) a fim de verificar a susceptibilidade para a doença em uma população do Sul do Brasil. Métodos: Foram analisados por sequenciamento direto de alta resolução os genes relacionados com os HLA DRB1, DQB1, DPB1, A, B e C em casos de EM comparados com uma população controle normal. Resultados: Foi encontrado uma frequência menor dos alelos dos HLA classe 1 e 2 nos casos de EM e controles quando comparado com a população Europeia. Diversos alelos mostraram correlação estatística, mas depois da correção de Bonferroni, somente o alelo do HLA-DQB1*02:03 foi positivo para a EM. Conclusões: Encontramos frequência diferente dos alelos do HLA relatados previamente nos Sudeste do Brasil e Europeus, possivelmente devido a origem étnica diferente da população estuda.

Palavras-chave: predisposição genética para doença; antígenos HLA; complexo principal de histocompatibilidade; esclerose múltipla.

The major histocompatibility complex (MHC), which is also known as the human leukocyte antigen system (HLA), is a set of specialized glycoproteins expressed on the surface of lymphocytes and encoded by genes located on chromosome 6p21.3. These glycoproteins are responsible for recognizing cells that contain a pathogenic organism, that are foreign to the body or whose surfaces have suffered changes ${ }^{1 .}$ Several polymorphisms have been found in the HLA genes, and this variability determines individual characteristics of the immune responses to infectious agents and foreign cells.
These responses are critical in cases of transplantation and in the pathogenesis of autoimmune diseases, such as ankylosing spondylitis, type 1 diabetes mellitus, narcolepsy, Reiter's syndrome, myasthenia gravis and multiple sclerosis (MS) ${ }^{1,2,3}$.

The first link between MS and HLA was reported in 1973 and involved HLA-DR2. A similar association for other HLA class II has since been reported by other authors, who assumed that the disease is related to patient ethnicity and possible to environmental factors that are unknown yet ${ }^{3,4}$. A strong correlation was found between MS and HLA-DRB1*15:01 in

${ }^{1}$ Universidade Federal do Paraná, Hospital de Clínicas, Departamento de Clínica Médica, Serviço de Neurologia, Curitiba PR, Brasil.

Correspondence: Lineu Cesar Werneck; Hospital de Clínicas; Rua General Carneiro, 181 / 3ªndar / sala 310; 80060-900 Curitiba PR, Brasil; E-mail: lineu. werneck@hc.ufpr.br

Conflict of interest: There is no conflict of interest to declare.

Support: This study was supported in part by Conselho Nacional de Desenvolvimento Científico e Tecnologico (CNPq), Coordenação de Aperfeiçoamento de Pessoal de Nivel Superior (CAPES), Serono and Biogen.

Received 18 May 2016; Received in final form 25 May 2016; Accepted 25 May 2016. 
northern European countries ${ }^{5}$; DRB1*15:01, DRB1*03:01 and $\mathrm{DRB1}^{*}$ 04:05 in Italy (Sardinia Islands) ${ }^{6}$; DRB1*15:01-DQA1 *01:02-DQB1*06:02, DRB1* 04:02-DQA1*03:01-DQB1*03:02 and DRB1*13:03-DQA1*05-DQB1*03:01 in Spain (in the province of Biscay) $)^{7}$; DRB1*15:01 and DQB1*0:602 in Ireland ${ }^{8}$; and $\mathrm{DRB}^{*} 04: 03$ and $\mathrm{DRB1}{ }^{* 08} 02$ in Mexico ${ }^{9}$. An association was also found between MS and the DQA1*01:02 and DQB1*06:02 haplotypes in African-Brazilian patients whether the DRB1*15:01 allele was absent ${ }^{10}$.

In recent years, researchers have turned their attention to HLA class I and its alleles. Initially performed with low resolution techniques, HLA typing showed that HLA-A*02 is negatively associated with the risk of MS (i.e., it is associated with a protective effect/reduction in susceptibility) regardless of the presence of the DRB ${ }^{*} 15$ allele ${ }^{11}$. Haplotype studies have shown that, HLA-A*02 reduces susceptibility to the disease (protective effect) when associated with HLA-B*12 and HLA-CW*05. The same occurred if this allele was associated with HLA-Cw*05 and HLA-B* $44^{11,12}$. The presence of the allele $\mathrm{CW}^{*} 05$ in the haplotype reduce the expression of HLA-B12 and DRB1*15 and the susceptibility to the disease ${ }^{11,13}$.

In light of the above, the aim of this study is to analyze the HLA class 1 and 2 profiles, with high resolutions technique, of MS patients of a Southern Brazil population to identify whether there is relationship between HLA type and susceptibility to MS in the Southern Brazilian population.

\section{METHODS}

\section{Patients and controls}

We analyzed 86 patients with a diagnosis of MS, 80 with the relapsing-remitting subtype and 6 with the primary progressive subtype, predominantly of white color, based on the 2010 McDonald criteria and 2013 revision $^{14}$. The cases had followed up at the demyelinating disease outpatient clinic at the Hospital de Clínicas, Universidade Federal do Paraná. MS patients who fulfilled the following criteria were included: (1) patient born in the south of Brazil and lived there for most of his/her life; (2) patient's complete medical records available (both clinical and laboratory data that information on the clinical course of the disease was available); (3) patient evaluated with the Expanded Disability Status Scale (EDSS) during treatment or follow-up or data in the patient's records sufficient to allow the disability to be graded; and (4) findings of patient's MRI studies compatible with MS. We excluded MS patients who had incomplete medical records, conflicting data, clinically isolated syndrome, neuromyelitis optica or incomplete outcome data that did not allow other diseases to be ruled out (Table 1).

The control group consisted of bone marrow donors who fulfilled the following criteria: 1) absence of any disease; 2) over 30 years old; 3) born and had always lived in southern Brazil; 4) only two unrelated members of the transplant recipient's household could be included (mother and father), and in the parents' absence only one sibling could be included; and 5) HLA screening performed in Curitiba at the Immunogenetics Laboratory, Hospital de Clínicas, Universidade Federal do Paraná (All data were kindly supplied by Dr. Noemi Farah Ferreira and her laboratory team). The number of controls included in the study was 606 donors for HLA-DRB1 (1212 alleles), 220 for HLA-DQB1 (440 alleles), 133 for HLA-DPB1 (266 alleles), 127 for HLA-A (254 alleles), 168 for HLA-B (336 alleles) and 111 for HLA-C (222 alleles).

The study was approved by the Ethics Committee for Research with Humans at the Hospital de Clínicas, Universidade Federal do Paraná. All patients agreed to participate and signed a consent form.

\section{HLA Typing}

Genomic DNA was extracted from blood using a standard phenol-chloroform technique after treatment with proteinase-K and then amplified by polymerase chain reaction (PCR) to obtain gene fragments (exons) related to HLA class I and II using oligonucleotides flanking specific regions of the following exons: HLA-A (exons 2, 3 and 4), HLA-B (exons 2, 3 and 4), HLA-C (exons 2, 3 and 4), HLA-DRB1 (exon 2), HLA-DPB1 (exon 2) and HLA-DQB1 (exons 2 and 3). PCR was performed separately for each exon of these different genes using a conventional method with Taq DNA polymerase (Abbott Molecular Diagnostics) and a SBT (sequence based typing) kit (AlleleSEQR-SBT) (Atria Genetics) following the manufacturers' instructions. PCR products were purified by ExoSAP-IT ${ }^{\circledast}$ (USB, Cleveland, Ohio). The purified

Table 1. Characteristics of multiple sclerosis (MS) patients and control group.

\begin{tabular}{lcc}
\hline Variable & MS $(n=86)$ & Controls $(n=606)$ \\
\hline Age & $\begin{array}{c}40.87 \pm 11.65 \\
(18-63)\end{array}$ & $\begin{array}{c}49.53 \pm 13.11 \\
(30-88)\end{array}$ \\
Age onset of symptoms & $\begin{array}{c}29.95 \pm 9.81 \\
(12-50)\end{array}$ & - \\
\hline Disease duration & $\begin{array}{c}10.91 \pm 6.87 \\
(1-34)\end{array}$ & - \\
\hline Initial EDSS score & $2.43 \pm 1.69(0-7.5)$ & - \\
\hline Follow-up EDSS score & $3.36 \pm 2.47$ & - \\
Gender & $(0-8.5)$ & \\
\hline Females & & $304(50.16 \%)$ \\
\hline Males & $60(69.8 \%)$ & $302(49.84 \%)$ \\
Color skin & $26(30.2 \%)$ & \\
\hline White & & $578(95.6 \%)$ \\
\hline Brown (mulatto) & $33(96.6 \%)$ & $11(1.8 \%)$ \\
\hline Black & 0 & $9(1.4 \%)$ \\
\hline Yellow (Asian) & 0 & $2(0.4 \%)$ \\
\hline Amerindian & 0 & \\
\hline
\end{tabular}

EDSS: expanded disability status scale. 
PCR products were then subjected to a second round of PCR using Big Dye Mix (Applied Biosystems) followed by purification of the products by the isopropanol method. The amplified fragments were directly sequenced in forward and reverse directions by fluorescent capillary electrophoresis using POP-6 polymer (Applied Biosystems, Foster City, CA) in an ABI PRISM 3100 and 3130 Avant Genetic Analyzers ${ }^{\circ}$ (Hitachi High-Technologies Corporation, Tokyo, Japan). The HLA sequences were compared with reference sequences by high-resolution HLA typing using Assign SBT software (Conexio-Genomics, Fremantle, Australia) and UTYPE ${ }^{\circ}$ HLA Analysis Software (Thermo Fisher Scientific, Waltham, MA).

\section{Statistical analysis}

Descriptive statistics were calculated for age (MS cases and controls) and age at onset of symptoms, EDSS score at disease onset and EDSS score at the last evaluation (MS cases). The relationships between the MS cases and controls were calculated with Pearson's chi-square test using Yates' correction. Statistical significance was considered for $\mathrm{p}<0.05$. These values were then corrected by Bonferroni methods according the number of alleles analyzed. The Odds Ratio was estimate with the Mantel-Haenszel statistic method.

\section{RESULTS}

The HLA-DRB1 was sequenced in 86 cases, HLA-DQB1 and DPB1 in 85, HLA-A in 64, HLA-B in 65 and HLA-C in 85. These data were not uniform because of ambiguities and technical artifacts found in some patients.

HLA-DRB1: We found 52 different alleles in MS and 44 in controls. Of those, 19 alleles occurred only in MS and 11 only in controls. The most common allele in MS patients and controls was DRB1*15:01, which was present in a higher percentage of individuals in the MS group. This was followed by *03:01 and *07:01 alleles. DRB1*15:01, "11:03 and *04:06 alleles. They were statistically significant to MS, but all of them were non significant after Bonferroni correction for the 63 alleles. The same occurred with DRB1*11:01 and *10:01 alleles in the controls (Table 2).

$H L A-D Q B 1$ : We found 35 different alleles in MS and 17 in controls. Of those, 19 alleles occurred only in MS and only 1 control did not have the same allele that MS. The most common allele was DQB1*06:02 in MS, followed by *02:01 and *03:02. The DQB1*02:03, *03:69 and *04:03 alleles were statistically significant, whereas in the controls DQB1 *03:01 and *02:02 alleles were more frequent. After the Bonferroni

Table 2. Frequency of the HLA-DRB1 in multiple sclerosis and control group.

\begin{tabular}{|c|c|c|c|c|c|c|c|}
\hline Alleles & MS & \multirow{2}{*}{$\%$} & Controls & \multirow{2}{*}{$\%$} & \multirow{2}{*}{$\mathrm{p}$} & \multirow{2}{*}{ OR $(95 \% \mathrm{Cl})$} & \multirow{2}{*}{$\mathrm{p}^{\mathrm{c}}$} \\
\hline DRB1 & 86 Cases & & 606 Cases & & & & \\
\hline *15:01 & 24 & 14.0 & 98 & 8.1 & 0.017 & $1.843(1.14-2.97)$ & NS \\
\hline *03:01 & 17 & 9.9 & 85 & 7.0 & 0.233 & $1.454(0.84-2.52)$ & NS \\
\hline$\star 07: 01$ & 16 & 9.3 & 180 & 14.9 & 0.066 & $0.588(034-1.00)$ & NS \\
\hline *13:01 & 11 & 6.4 & 71 & 5.9 & 0.643 & $0.784(0.37-1.65)$ & NS \\
\hline *13:02 & 8 & 4.7 & 38 & 3.1 & 0.418 & $1.507(0.69-3.28)$ & NS \\
\hline *11:04 & 7 & 4.1 & 32 & 2.6 & 0.416 & $1.564(0.68-3.60)$ & NS \\
\hline *01:01 & 6 & 3.5 & 52 & 4.3 & 0.164 & $0.396(0.12-1.28)$ & NS \\
\hline *04:04 & 6 & 3.5 & 33 & 2.7 & 0.748 & $1.291(0.53-3.13)$ & NS \\
\hline *01:02 & 4 & 2.3 & 22 & 1.8 & 0.872 & $1.288(0.43-3.78)$ & NS \\
\hline$\star 08: 01$ & 4 & 2.3 & 32 & 2.6 & 1.000 & $0.878(0.31-2.51)$ & NS \\
\hline *08:07 & 4 & $2 ; 3$ & 8 & 0.7 & 0.078 & $3.583(1.07-12.03)$ & NS \\
\hline *11:01 & 4 & 2.3 & 79 & 6.5 & 0.046 & $0.341(0.12-0.94)$ & NS \\
\hline *16:01 & 4 & 2.3 & 29 & 2.4 & 1.000 & $0.971(0.34-2.80)$ & NS \\
\hline *04:02 & 3 & 1.7 & 30 & 2.5 & 0.748 & $0.699(0.21-2.31)$ & NS \\
\hline *11:03 & 3 & 1.7 & 3 & 0.2 & 0.030 & $7.154(1.43-35.73)$ & NS \\
\hline *14:01 & 3 & 1.7 & 63 & 5.2 & 0.072 & $0.324(0.10-1.04)$ & NS \\
\hline$\star 04: 06$ & 2 & 1.2 & 0 & 0 & 0.007 & 0 & NS \\
\hline *10:01 & 0 & 0 & 44 & 3.6 & 0.021 & 0 & NS \\
\hline \multirow{2}{*}{ Others alleles } & 35 Cases & - & 27 Cases & - & \multirow{2}{*}{-} & \multirow{2}{*}{-} & \multirow{2}{*}{ NS } \\
\hline & 46 & 26.8 & 313 & 25.9 & & & \\
\hline Total & 172 & 100 & 1212 & 100 & - & - & - \\
\hline
\end{tabular}

MS: multiple sclerosis; p: probability; OR: odds ratio; Cl: confidence interval; $\mathrm{p}^{c}$ : probability after Bonferroni correction for 53 multiple comparisons for $\mathrm{p}<0.05$; NS: non significant. 
correction for 36 alleles, only the allele $\mathrm{DQB1}{ }^{*} 02: 03$ was significant $(\mathrm{p}=0.0027)$ (Table 3$)$.

HLA-DPB1: We found 30 different alleles in MS and 22 in controls. In MS, 14 alleles occurred only in this group and 6 controls did not have similar MS allele. The most common alleles in the MS group and controls were *04:01, "02:01 and *04:02. The *23:01 and *51:01 alleles were statistically significant, but they lost the significance after Bonferroni correction for the 36 alleles (Table 4).

HLA-A: We found 42 different alleles in MS and 32 in controls. In MS, 22 alleles occurred only in this group and 12 controls did not have similar allele in MS. The most common alleles in the MS group were *03:01 and *24:02. The alleles *24:02 and *02:01 had statistical significance, but they become non significant after Bonferroni correction for the 57 alleles (Table 5).

$H L A-B$ : We found 60 different alleles in MS and 76 in controls. In MS group, 25 alleles did not occurred in the controls and 42 of the controls did not have similar allele in MS group. The most common allele in the MS group and controls were *07:02, *51:01 and *35:01. There is a statistical relation with alleles *35:01, *44:02, *14:06, and *52:01, but all of them lost the statistical significance after Bonferroni correction for the 97 alleles (Table 6).

$H L A-C$ : We found 39 different alleles in MS and 30 in controls. In MS group, 20 alleles did not occurred in controls and
11 of the controls did not have the same MS allele. The most common alleles in the MS group and controls were *04:01, *07:02 and *08:02. HLA-C*07:27 was the only allele with statistical correlation, but it lost the significance after Bonferroni correction (Table 7).

\section{DISCUSSION}

HLA-DRB1*15:01 is considered a major susceptibility allele, but other HLA alleles in the haplotype, as well as the way that they were transmitted, can increase or decrease this susceptibility. These other alleles (of the same or different class) can determine epistatic interactions and modifications or epigenetic variations that may change the expression of nearby genes, determining greater or lesser susceptibility to $\mathrm{MS}^{13,15,16}$.

Although the frequency of DRB1*15:01 in our study was increased, the frequencies of this and other alleles were lower for both, MS patients and controls, compared with that reported in Europeans ${ }^{17}$. We found association but after the Bonferroni correction disappeared. This difference may be explained by the number of cases studied and the influence of the mixing of European, African and indigenous genes in Brazil $^{18}$ (Figure 1).

In three Brazilian studies the percentage of the DRB1*15:01 allele was high, especially in white individuals ${ }^{19,20}$ and women ${ }^{21}$.

Table 3. Frequency of the HLA-DQB1 in multiple sclerosis and control group.

\begin{tabular}{|c|c|c|c|c|c|c|c|}
\hline Allele & MS & \multirow{2}{*}{$\%$} & Controls & \multirow{2}{*}{$\%$} & \multirow{2}{*}{$p$} & \multirow{2}{*}{ OR (95\% Cl) } & \multirow{2}{*}{$\mathrm{p}^{\mathrm{c}}$} \\
\hline DQB1 & 85 cases & & 220 cases & & & & \\
\hline *06:02 & 29 & 17.1 & 55 & 12.5 & 0.182 & $1.440(0.88-2.35)$ & NS \\
\hline *02:01 & 18 & 10.6 & 42 & 9.5 & 0.813 & $1.122(0.62-2.01)$ & NS \\
\hline *03:02 & 16 & 9.4 & 40 & 9.1 & 1.000 & $1.039(0.56-1.91)$ & NS \\
\hline *03:01 & 15 & 8.8 & 84 & 19.1 & 0.003 & $0.410(0.30-0.79)$ & NS \\
\hline$\star 05: 01$ & 13 & 7.6 & 53 & 12.0 & 0.155 & $0.605(0.32-1.14)$ & NS \\
\hline *04:02 & 12 & 7.1 & 21 & 4.8 & 0.358 & $1.515(0.73-3.15)$ & NS \\
\hline *06:03 & 9 & 5.3 & 27 & 6.1 & 0.838 & $0.855(0.39-1.86)$ & NS \\
\hline *02:02 & 6 & 3.5 & 49 & 11.1 & 0.005 & $0.292(0.12-0.69)$ & NS \\
\hline$\star 02: 03$ & 6 & 3.5 & 0 & 0 & 0.000 & 0 & 0.0027 \\
\hline *05:03 & 5 & 2.9 & 13 & 3.0 & 1.000 & $0.995(0.50-2.84)$ & NS \\
\hline *05:02 & 4 & 2.4 & 10 & 2.3 & 1.000 & $1.036(0.32-3.35)$ & NS \\
\hline *06:08 & 4 & $2 ; 4$ & 0 & 0 & 0.008 & 0 & NS \\
\hline *03:69 & 3 & 1.8 & 0 & 0 & 0.032 & $0-$ & NS \\
\hline *04:03 & 3 & 1.8 & 0 & 0 & 0.032 & $0-$ & NS \\
\hline *06:09 & 2 & 1.2 & 3 & 0.7 & 0.915 & $1.734(0.29-10.47)$ & NS \\
\hline *06:11 & 2 & 1.2 & 0 & 0 & 0.136 & 0 & NS \\
\hline \multirow{2}{*}{ Other alelles } & 20 cases & - & 6 Cases & - & \multirow{2}{*}{-} & \multirow{2}{*}{-} & \multirow{2}{*}{ NS } \\
\hline & 23 & 13.4 & 43 & 9.8 & & & \\
\hline Total & 170 & $100 \%$ & 440 & $100 \%$ & - & - & - \\
\hline
\end{tabular}

MS: multiple sclerosis; p: probability; OR: odds ratio; Cl: confidence interval; $\mathrm{p}^{c}$ : probability after Bonferroni correction for 36 multiple comparisons for $\mathrm{p}<0.05$; NS: non significant. 
Table 4. Frequency of the HLA-DPB1 in multiple sclerosis and control group.

\begin{tabular}{|c|c|c|c|c|c|c|c|}
\hline Allele & MS & \multirow{2}{*}{$\%$} & Controls & \multirow{2}{*}{$\%$} & \multirow{2}{*}{$\mathrm{p}$} & \multirow{2}{*}{ OR $(95 \% \mathrm{Cl})$} & \multirow{2}{*}{$\mathrm{p}^{\mathrm{c}}$} \\
\hline DPB1 & 85 Cases & & 133 Cases & & & & \\
\hline$\star 04: 01$ & 44 & 25.9 & 68 & 25.6 & 1.000 & $0.017(0.65-1.58)$ & NS \\
\hline$\star 02: 01$ & 18 & 10.6 & 37 & 13.9 & 0.384 & $0.733(0.40-1.33)$ & NS \\
\hline$\star 04: 02$ & 18 & 10.6 & 40 & 15.0 & 0.234 & $0.669(0.37-1.21)$ & NS \\
\hline *03:01 & 12 & 7.1 & 32 & 12.0 & 0.129 & $0.55(0.28-1.11)$ & NS \\
\hline$\star 01: 01$ & 10 & 5.9 & 14 & 5.3 & 0.951 & $1.125(0.49-2.59)$ & NS \\
\hline$\star 05: 01$ & 9 & 5.3 & 10 & 3.8 & 0.600 & $1.431(0.57-3.60)$ & NS \\
\hline *10:01 & 9 & 5.3 & 9 & 3.4 & 0.465 & $1.596(0.62-4.106)$ & NS \\
\hline *23:01 & 9 & 5.3 & 1 & 0.4 & 0.003 & $14.814(1.90-118.01)$ & NS \\
\hline *14:01 & 5 & 2.9 & 12 & 4.5 & 0.567 & $0.641(0.22-1.85)$ & NS \\
\hline *13:01 & 4 & 2.4 & 6 & 2.3 & 1.000 & $1.044(0.29-3.76)$ & NS \\
\hline *51:01 & 4 & 2.4 & 0 & 0 & 0.046 & 0 & NS \\
\hline$\star 71: 01$ & 3 & 1.8 & 0 & 0 & 0.114 & 0 & NS \\
\hline$\star 06: 01$ & 2 & 1.2 & 4 & 1.5 & 1.000 & $0.780(0.14-4.30)$ & NS \\
\hline *11:01 & 2 & 1.2 & 10 & 3.8 & 0.191 & $0.305(0.07-1.41)$ & NS \\
\hline$\star 20: 01$ & 2 & 1.2 & 0 & 0 & 0.295 & 0 & NS \\
\hline$\star 57: 01$ & 2 & 1.2 & 0 & 0 & 0.295 & 0 & NS \\
\hline \multirow{2}{*}{ Other alelles } & 14 Cases & - & 10 Cases & - & \multirow{2}{*}{-} & \multirow{2}{*}{-} & \multirow{2}{*}{-} \\
\hline & 17 & 9.7 & 27 & 8.5 & & & \\
\hline Total & 170 & 100 & 266 & 100 & - & - & - \\
\hline
\end{tabular}

MS: multiple sclerosis; p: probability; OR: odds ratio; Cl: confidence interval; $\mathrm{p}^{c}$ : probability after Bonferroni correction for 36 multiple comparisons for $\mathrm{p}<0.05$; NS: non significant.

Table 5. Frequency of the in multiple sclerosis and control group.

\begin{tabular}{|c|c|c|c|c|c|c|c|}
\hline Allele & MS & \multirow{2}{*}{$\%$} & Controls & \multirow{2}{*}{$\%$} & \multirow{2}{*}{$\mathrm{p}$} & \multirow{2}{*}{ OR $(95 \% \mathrm{Cl})$} & \multirow{2}{*}{$\mathrm{p}^{\mathrm{c}}$} \\
\hline HLA-A & 62 cases & & 195 cases & & & & \\
\hline 03:01 & 20 & 16.1 & 37 & 9.5 & 0.040 & $1.835(1.021-3.297)$ & NS \\
\hline 24:02:00 & 17 & 13.7 & 39 & 10.0 & 0.322 & $1.430(0.777-2.630)$ & NS \\
\hline 02:01 & 11 & 8.9 & 79 & 20.3 & 0.004 & $0.383(0.197-0.746)$ & NS \\
\hline 01:01 & 11 & 8.9 & 42 & 10.8 & 0.663 & $0.807(0.402-1.619)$ & NS \\
\hline 23:01 & 7 & 5.6 & 19 & 4.9 & 0.915 & $1.168(0.479-2.848)$ & NS \\
\hline 68:01:00 & 5 & 4.0 & 10 & 2.6 & 0.589 & $1.597(0.535-4.763)$ & NS \\
\hline $11: 01$ & 5 & 4.0 & 16 & 4.1 & 1.000 & $0.982(0.352-2.738)$ & NS \\
\hline 68:02:00 & 4 & 3.2 & 4 & 1.0 & 0.191 & $3.217(0.792-13.057)$ & NS \\
\hline $31: 01: 00$ & 3 & 2.4 & 21 & 5.4 & 0.270 & $0.439(0.129-1.499)$ & NS \\
\hline 25:01:00 & 3 & 2.4 & 6 & 1.5 & 0.796 & $1.587(0.391-6.440)$ & NS \\
\hline 32:01:00 & 2 & 1.6 & 13 & 3.3 & 0.493 & $0.475(0.106-2.136)$ & NS \\
\hline 26:01:00 & 2 & 1.6 & 11 & 2.8 & 0.676 & $0.565(0.123-2.584)$ & NS \\
\hline 33:01:00 & 2 & 1.6 & 6 & 1.5 & 1.000 & $1.049(0.209-5.266)$ & NS \\
\hline 29:02:00 & 1 & 0.8 & 15 & 3.8 & 0.161 & $0.203(0.027-1.554)$ & NS \\
\hline $30: 01: 00$ & 0 & 0 & 11 & 2.8 & 0.059 & 0 & NS \\
\hline 03:02 & 0 & 0 & 8 & 2.1 & 0.234 & 0 & NS \\
\hline \multirow{2}{*}{ Other alleles } & 28 cases & - & 21 cases & - & \multirow[t]{2}{*}{-} & \multirow[t]{2}{*}{-} & \multirow{2}{*}{ NS } \\
\hline & 31 & 25.2 & 53 & 13.6 & & & \\
\hline Total & 124 & 100 & 390 & 100 & - & - & - \\
\hline
\end{tabular}

MS: multiple sclerosis; p: probability; OR: odds ratio; Cl: confidence interval; $\mathrm{p}^{\mathrm{c}}$ : probability after Bonferroni correction for 57 multiple comparisons for $\mathrm{p}<0.05$. NS: non significant. 
Table 6. Frequency of HLA-B in multiple sclerosis and control group.

\begin{tabular}{|c|c|c|c|c|c|c|c|}
\hline Allele & MS & \multirow{2}{*}{$\%$} & Controls & \multirow{2}{*}{$\%$} & \multirow{2}{*}{$\mathrm{p}$} & \multirow{2}{*}{ OR (95\%Cl) } & \multirow{2}{*}{$\mathrm{p}^{\mathrm{c}}$} \\
\hline HLA B & 69 cases & & 234 cases & & & & \\
\hline 07:02 & 15 & 10.9 & 31 & 6,6 & 0.098 & $1.719(0.899-3.287)$ & NS \\
\hline $35: 01: 00$ & 10 & 7.2 & 11 & 2,4 & 0.012 & $3.246(1.348-7.814)$ & NS \\
\hline 51:01:00 & 10 & 7.2 & 16 & 3,4 & 0.051 & $2.207(0.978-4.982)$ & NS \\
\hline $14: 02$ & 7 & 5.1 & 21 & 4.5 & 0.773 & $1.137(0.473-2.735)$ & NS \\
\hline 18:01 & 7 & 5.1 & 11 & 2.4 & 0.171 & $2.220(0.844-5.841)$ & NS \\
\hline 44:02:00 & 7 & 5.1 & 7 & 1.5 & 0.033 & $3.519(1.213-10.213)$ & NS \\
\hline 08:01 & 5 & 3.6 & 19 & 4.1 & 1.000 & $0.888(0.326-2.424)$ & NS \\
\hline $14: 01$ & 5 & 3.6 & 8 & 1.7 & 0.303 & $2.162(0.696-6.718)$ & NS \\
\hline $15: 01$ & 5 & 3.6 & 13 & 2.8 & 0.819 & $1.316(0.461-3.758)$ & NS \\
\hline $14: 06$ & 3 & 2.2 & 0 & 0 & 0.012 & 0 & NS \\
\hline 40:01:00 & 3 & 2.2 & 4 & 0.9 & 0.411 & $2.578(0.570-11.659)$ & NS \\
\hline 41:01:00 & 3 & 2.2 & 1 & 0.2 & 0.057 & $10.378(1.071-100.577)$ & NS \\
\hline 49:01:00 & 3 & 2.2 & 10 & 2.1 & 1.000 & $1.108(0.276-3.751)$ & NS \\
\hline $52: 01: 00$ & 1 & 0.7 & 24 & 5.1 & 0.041 & $0.135(0.018-1.007)$ & NS \\
\hline $15: 03$ & 1 & 0.7 & 15 & 3.2 & 0.195 & $0.220(0.029-1.684)$ & NS \\
\hline $38: 01: 00$ & 0 & 0 & 10 & 2.1 & 0.177 & 0 & NS \\
\hline \multirow{2}{*}{ Other alleles } & 45 cases & & 59 cases & - & \multirow{2}{*}{ - } & \multirow{2}{*}{-} & \multirow{2}{*}{ NS } \\
\hline & 53 & 38.4 & 267 & 55.0 & & & \\
\hline Total & 138 & 100 & 468 & 100 & - & - & - \\
\hline
\end{tabular}

MS: multiple sclerosis; p: probability; OR: odds ratio; Cl: confidence interval; pc: probability after Bonferroni correction for 54 multiple comparisons for $\mathrm{p}<0.05$; NS: non significant.

Table 7. Frequency of the HLA-C in multiple sclerosis and control group.

\begin{tabular}{|c|c|c|c|c|c|c|c|}
\hline Allele & MS & \multirow{2}{*}{$\%$} & Controls & \multirow{2}{*}{$\%$} & \multirow{2}{*}{$p$} & \multirow{2}{*}{ OR $(95 \% \mathrm{Cl})$} & \multirow{2}{*}{$p^{c}$} \\
\hline HLA-C & 85 Cases & & 111 Cases & & & & \\
\hline *04:01 & 26 & 15.3 & 32 & 14.4 & 0.921 & $1.072(0.61-1.88)$ & NS \\
\hline *07:02 & 24 & 14.1 & 31 & 14.0 & 1.000 & $1.013(0.57-1.80)$ & NS \\
\hline *08:02 & 13 & 7.6 & 9 & 4.1 & 0.190 & $1.960(0.82-4.70)$ & NS \\
\hline *05:01 & 11 & 6.5 & 11 & 5.0 & 0.671 & $1.327(0.56-3.14)$ & NS \\
\hline *07:01 & 10 & 5.9 & 21 & 9.5 & 0.266 & $0.598(0.27-1.31)$ & NS \\
\hline *03:04 & 9 & 5.3 & 13 & 5.9 & 0.986 & $0.899(0.37-2.15)$ & NS \\
\hline *06:02 & 9 & 5.3 & 25 & 11.3 & 0.58 & $0.440(0.20-0.97)$ & NS \\
\hline *01:02 & 7 & 4.1 & 4 & 1.8 & 0.286 & $2.340(0.67-8.13)$ & NS \\
\hline *03:03 & 7 & 4.1 & 9 & 4.1 & 1.000 & $1.016(0.37-2.79)$ & NS \\
\hline *12:03 & 6 & 3.5 & 13 & 5.9 & 0.409 & $0.588(0.22-1.58)$ & NS \\
\hline$\star 07: 27$ & 5 & 2.9 & 0 & 0 & 0.034 & 0 & NS \\
\hline *15:02 & 5 & 2.9 & 2 & 0.9 & 0.260 & $3.333(0.64-17.39)$ & NS \\
\hline$\star 17: 01$ & 5 & 2.9 & 3 & 1.4 & 0.458 & $2.212(0.52-9.39)$ & NS \\
\hline$\star 02: 02$ & 4 & 2.4 & 10 & 4.5 & 0.388 & $0.511(0.16-1.66)$ & NS \\
\hline$\star 04: 09$ & 2 & 1.2 & 0 & 0 & 0.365 & 0 & NS \\
\hline$\star 14: 02$ & 2 & 1.2 & 0 & 0 & 0.365 & 0 & NS \\
\hline$\star 15: 05$ & 2 & 1.2 & 3 & 1.4 & 1.000 & $0.869(0.14-5.26)$ & NS \\
\hline \multirow{2}{*}{ Other } & 22 cases & - & 16 cases & - & \multirow{2}{*}{-} & \multirow{2}{*}{-} & \multirow{2}{*}{ NS } \\
\hline & 23 & 13.6 & 36 & 15.8 & & & \\
\hline Total & 170 & 100 & 222 & 100 & - & - & - \\
\hline
\end{tabular}

MS: multiple sclerosis; p: probability; OR: ODDS RATIO; Cl: confidence interval; $\mathrm{p}^{c}$ : probability after Bonferroni correction for 54 multiple comparisons for $\mathrm{p}<0.05$; NS: non significant. 
However, they mixed high-resolution with low-resolution techniques, as well as they have a low number of controls population to identify the DRB1*15:01 allele.

Although DQB1*06:02 was the most frequent allele, we failed to find an association between this allele and MS, as reported in
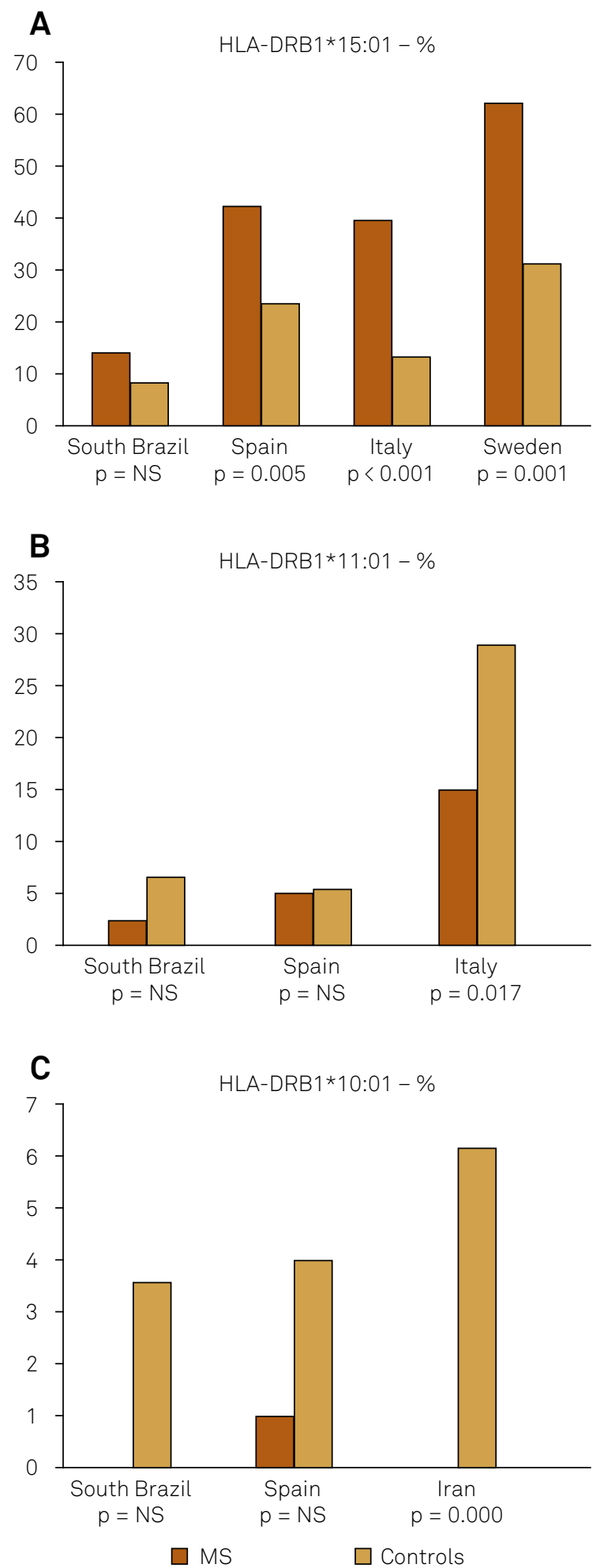

Figure 1. (A) Frequency of HLA-DRB1*15:01 alleles in South Brazil, Spain ${ }^{7}$, Italy ${ }^{6}$ and Sweden 5 ; (B) Frequency of HLA DRB1*11:01 alleles in South Brazil, Spain ${ }^{7}$ and Italy ${ }^{16}$; (C) Frequency of HLA-DRB1*10:01 alleles in South Brazil, Spain ${ }^{7}$ and Iran ${ }^{23}$.
Spain (Basque Country) ${ }^{7}$, Ireland ${ }^{8}$, Italy (Sardinia) $)^{22}$, $\operatorname{Iran}^{23}$, China (Hong Kong) ${ }^{24}$, Colombia ${ }^{25}$ and Afro-Brazilian (Rio de Janeiro) ${ }^{10}$. The only DQB1 allele which remained with statistical significance after Bonferroni correction was the *02:03. This association was not previously reported.

The allele DQB1*03:01 was associated with MS in Spain ${ }^{7}$ but have a reduced susceptibility in $\operatorname{Iran}^{23}$. However, previous studies showed that the risk of MS increases by $50 \%$ in the presence of HLA-DPB1*03:01 26 (Figure 2).

In the analysis of HLA-DPB1, we did not find the *03:01 allele associated with MS, as reported in Italy (Sardinia) ${ }^{6}$ and several European countries ${ }^{26}$. Although this association was only found in the absence of DQB1*06:02 allele in Australia ${ }^{27}$. The DPB1*05:01 allele showed no association with MS in our series, in contrast with the findings for other series from South China ${ }^{28}$ (Figure 3).

In our series, before Bonferroni correction, there was a positive association between MS and HLA-A*03:01 (increased susceptibility) and a negative association for HLA-A*02:01 (increased in controls, protective effect). The reduced susceptibility to MS (protective effect) of HLA-A*02:01, *68:01, *02:05 and *06:06 alleles have been reported $^{26}$. It has been shown that if HLA-A*03:01 allele is associated with HLA-B*07:02 allele, the risk of MS increases, but if it is associated with HLA-A*02:01 allele, the risk is reduced ${ }^{5}$ (Figure 4).

HLA-B*35:01, *44:02, and *14:06 alleles were correlated with disease susceptibility in our series, but after Bonferroni correction no allele had significance. It is reported that the HLA-B*44 allele when present reduce susceptibility to MS, slowing disease progression and preserving brain volume in North American patients ${ }^{15,29}$. However, in our series, it was more frequent in MS cases, than the previous reports, which have more cases in the control groups (Figure 5).

HLA-C *07:27 allele was found only in the MS group, suggesting an association with susceptibility to the disease. In addition, our results failed to reveal an association between HLA-C*05, which was shown to have a protective effect in some MS population ${ }^{29}$. However, it is difficult to make any correlation of the HLA-C because most of the previous studies are in low resolution.

Our HLA results probably could be explained by two main hypothesis: first, the different distribution of the ethnic background into Brazil; and second, the different resolutions techniques used in the previous studies.

Regarding the ethnic Brazilian background, the differences found comparing with Europeans could be due to the variation in the Brazilian population because of the many immigrants with different ethnic backgrounds who arrived in Brazil and gradually mixed with the local inhabitants over the last 500 years $^{30}$.

Brazil was colonized mainly by the Portuguese, who mixed with native Brazilian Indians in the first centuries following colonization. Later, African slaves were introduced to 
the country, mainly to the Southeast and Northeast to work on sugarcane plantations. In the mid $19^{\text {th }}$ century European immigrants began to arrive in Brazil. However, they did not settle evenly throughout the country and tended to concentrate in certain areas according to their ethnic descent ${ }^{30}$.

The Southeast, for example, had large numbers of Portuguese and Spanish people from Galicia, as well as Arabs, Jews and
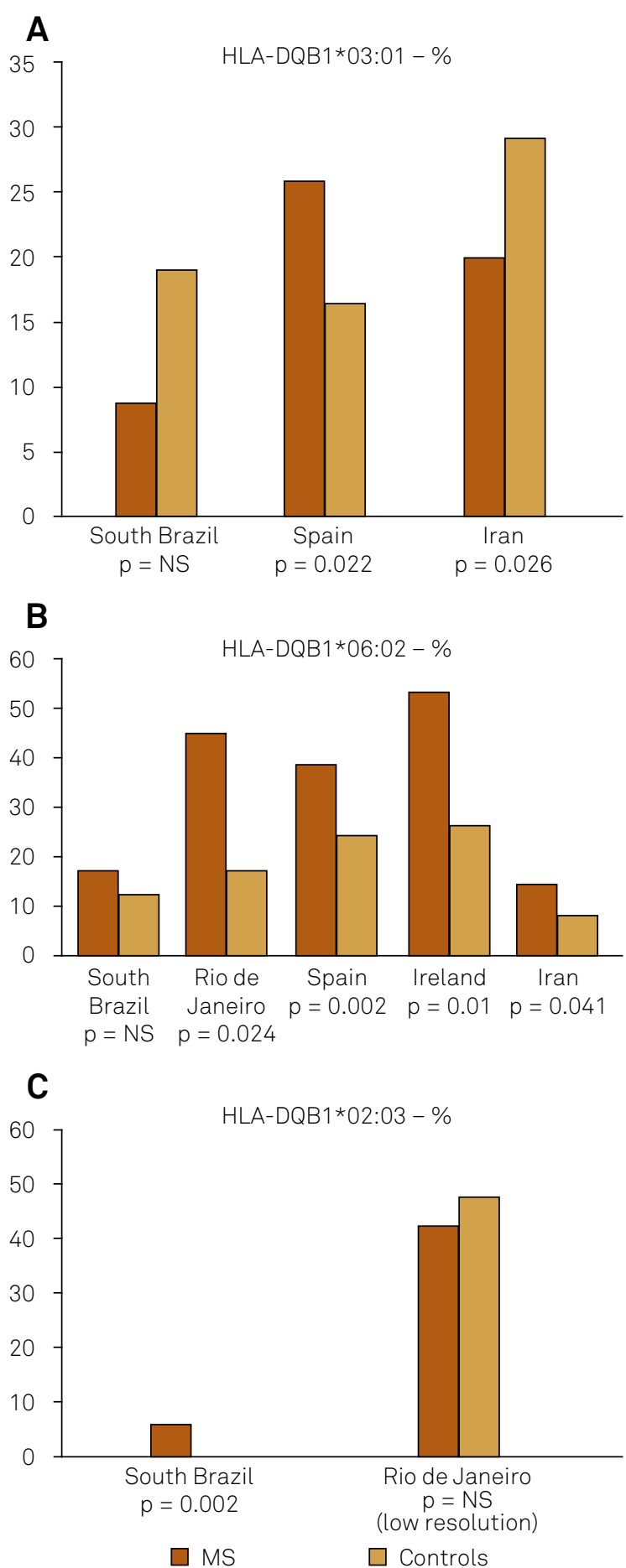

Figure 2. (A) Frequency of HLA-DQB1*03:01 allele in South Brazil, Spain ${ }^{7}$ and Iran' ${ }^{23}$; (B) Frequency of HLA-DQB1*06:02 allele in South Brazil, Rio de Janeiro (Afro-Brazilian) ${ }^{10}$, Spain 7 , Ireland ${ }^{8}$ and $\operatorname{Iran}^{23}$; (C) Frequency of HLA-DQB1*02:03 allele in South Brazil and Rio de Janeiro (Afro-Brazilian) ${ }^{19}$.

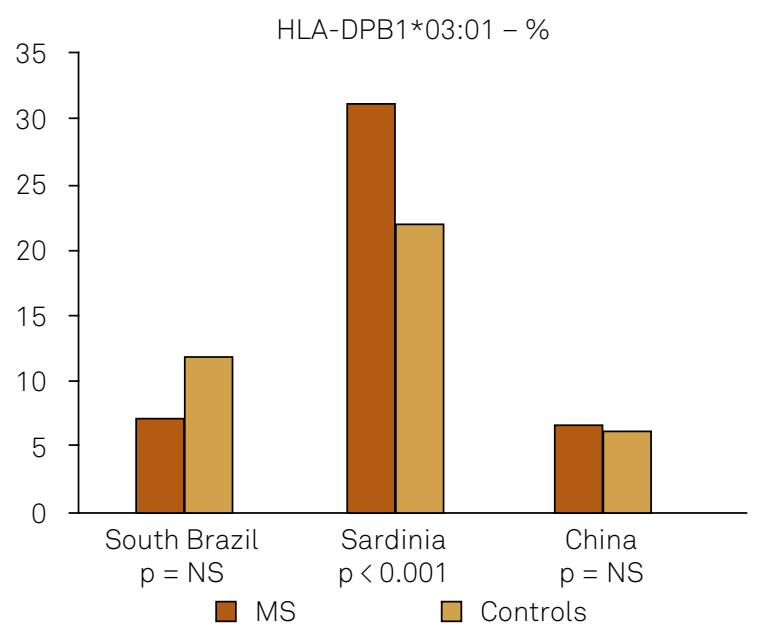

Figure 3. Frequency of HLA-DPB1*03:01 allele in South Brazil, Sardinia $(\text { Italy })^{6}$ and China ${ }^{28}$.

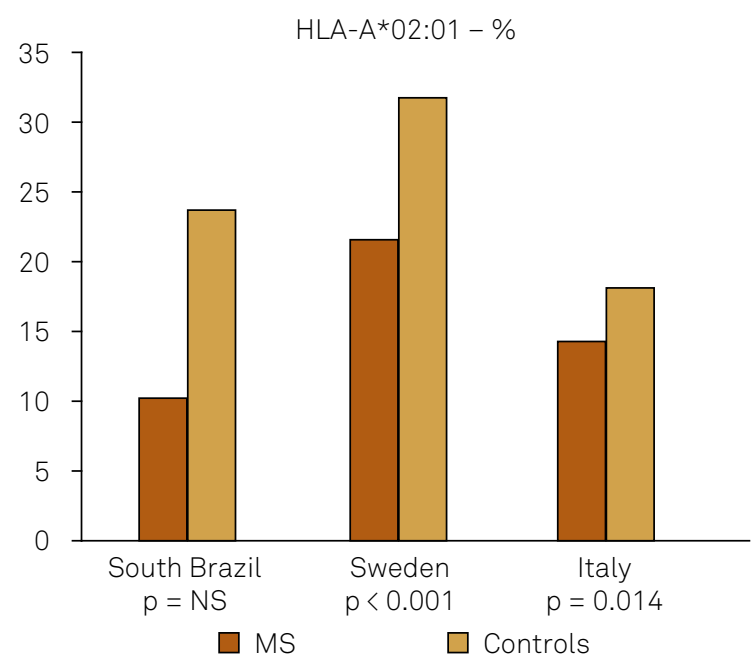

Figure 4. Frequency of HLA-A*02:01 allele in South Brazil, Sweden ${ }^{5}$ and Italy ${ }^{16}$.

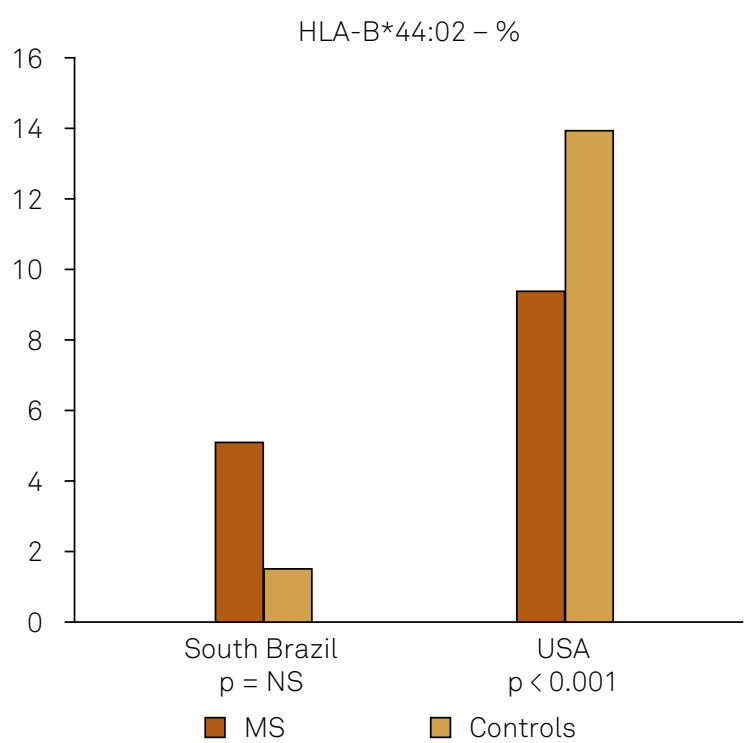

Figure 5. Frequency of HLA-B*44:02 allele in South Brazil and United States ${ }^{17}$. 
Japanese in smaller numbers. The Italians settled in the Southeast and South and constituted one of the largest immigrant population in Brazil, while the Germans, Polish and Ukrainians settled mainly in the South ${ }^{30}$.

Genetic studies have shown that the white Brazilian population has genes of Europeans, African and indigenous origin. The distribution of these European genes is higher in the South (where our study was done), there is a greater proportion of white individuals and a smaller proportion of black individuals in this area ${ }^{31}$.

Regarding the different resolutions techniques used in the previous studies, the admixture of the population of several ethnic origins increased the number of different alleles which are easier to analyses with techniques of high resolution. At present time, if the typing the HLA was performed only with high resolutions techniques, the number of alleles in each class increased too much (http://hla.alleles.org/alleles/class1.html; http://hla.alleles.org/alleles/class2.html). Therefore, if the Bonferroni correction was applied in this situation (for the total number of alleles), most of the studies lost their statistical significance.

In some of the previous HLA studies performed in Brazil, the analysis grouped together techniques of low and high resolution, which rise difficulties to compare with our results that were performed only with high resolution techniques ${ }^{10,19,20}$.

We believe that the mainly factor to our different results was the different ethnic backgrounds into Brazil which can really results in many possible genetic combinations in the Brazilian population. Furthermore, beside the type of HLA and ethnic diversity, probably climate with less sunlight, different environmental conditions and dietary habits could play a role in the triggering and incidence of MS in southern Brazil different from other countries ${ }^{8,32,33,34,35}$.

In conclusion, our data have different frequency of HLA alleles in Southern Brazilian population than the previous published with the Southeast Brazil region and Europeans. We also speculate that further studies of HLA regarding the MS susceptibility in the European Countries in the next century may find different results from today when using high resolution techniques and large control groups. We do not know the effect of the dilution of the original HLAs alleles due to the massive immigration which is occurring in the present days, similar that occurred with the original Brazilians inhabitants over the last 500 years.

\section{Acknowledgements}

We would like to thanks Dr. Noemi Farah Ferreira, colleagues and technicians at the Immunogenetics Laboratory, Hospital de Clínicas, Federal University of Paraná, Curitiba, Brazil. The authors would also like to thank Dr. Monica F. Parolin and Dr. Flávia Folador for patient referral.

\section{References}

1. Murphy K, Travers P, Walport M. Janeways's immunobiology. 7th ed. New York: Garland Science; 2008. p. 196-212.

2. Ramagopalan SV, Ebers GC. Multiple sclerosis: major histocompatibility complexity and antigen presentation. Genome Med. 2009;1(11):105. doi:10.1186/gm105

3. Barcellos LF, Sawcer S, Ramsay PP, Baranzini SE, Thomson G, Briggs F et al. Heterogeneity at the HLA-DRB1 locus and risk for multiple sclerosis. Hum Mol Genet. 2006;15(18):2813-24. doi:10.1093/hmg/ddl223

4. Lincoln MR, Ramagopalan SV, Chao MJ, Herrera BM, Deluca GC, Orton SM et al. Epistasis among HLA-DRB1, HLA-DQA1, and HLA-DQB1 loci determines multiple sclerosis susceptibility. Proc Natl Acad Sci USA. 2009;106(18):7542-7. doi:10.1073/pnas.0812664106

5. Sawcer S, Hellenthal G, Pirinen M, Spencer CC, Patsopoulos NA, Moutsianas L et al. Genetic risk and a primary role for cell-mediated immune mechanism in multiple sclerosis. Nature. 2011;476(7359):214-9. doi:10.1038/nature10251

6. Marrosu MG, Murru R, Murru MR, Costa G, Zavattari P, Whalen M et al. Dissection of the HLA association with multiple sclerosis in the founder isolated population of Sardinia. Hum Mol Genet. 2001;10(25):2907-26. doi:10.1093/hmg/10.25.2907

7. Fernández $\mathrm{O}, \mathrm{R}$-Antigüedad A, Pinto-Medel MJ, Mendibe MM, Acosta N, Oliver B et al. HLA class II alleles in patients with multiple sclerosis in the Biscay province (Basque Country, Spain). J Neurol. 2009;256(12):1977-88. doi:10.1007/s00415-009-5223-2

8. McGuigan C, McCarthy A, Quigley C, Bannan L, Hawkins SA, Hutchinson M. Latitudinal variation in the prevalence of multiple sclerosis in Ireland, an effect of genetic diversity. J Neurol Neurosurg Psychiatry. 2004;75(4):572-6. doi:10.1136/jnnp.2003.012666
9. Aláez C, Corona T, Ruano L, Flores H, Loyola M, Gorodezky C. Mediterranean and Amerindian MHC class II alleles are associated with multiple sclerosis in Mexicans. Acta Neurol Scand. 2005;112(5):317-22. doi:10.1111/j.1600-0404.2005.00493.x

10. Caballero A, Alvés-León S, Papais-Alvarenga R, Fernández O, Navarro G, Alonso A. DQB1*0602 confers genetic susceptibility to multiple sclerosis in Afro-Brazilians. Tissue Antigens. 1999;54(5):524-6. doi:10.1034/j.1399-0039.1999.540511.x

11. Link J, Kockum I, Lorentzen AR, Lie BA, Celius EG, Westerlind H et al. Importance of human leukocyte antigen (HLA) class I and II alleles on the risk of multiple sclerosis. PLoS One. 2012;7(5):e36779. doi:10.1371/journal.pone.0036779

12. Bergamaschi L, Ban M, Barizzone N, Leone M, Ferrante D, Fasano ME et al. Association of HLA class I markers with multiple sclerosis in the Italian and UK population: evidence of two independent protective effects. J Med Genet. 2011;48(7):485-92. doi:10.1136/jmg.2010.080721

13. Yeo TW, De Jager PL, Gregory SG, Barcellos LF, Walton A, Goris A et al. A second major histocompatibility complex susceptibility locus for multiple sclerosis. Ann Neurol. 2007;61(3):228-36. doi:10.1002/ana.21063

14. Lublin FD, Reingold SC, Cohen JA, Cutter GR, Sørensen PS, Thompson AJ et al. Defining the clinical course of multiple sclerosis: the 2013 revisions. Neurology. 2014;83(3):278-86. doi:10.1212/WNL.0000000000000560

15. Cree BA, Rioux JD, McCauley JL, Gourraud PA, Goyette P, McElroy J et al. A major histocompatibility Class I locus contributes to multiple sclerosis susceptibility independently from HLA-DRB1*15:01. PLoS One. 2010;5(6):e11296. doi:10.1371/journal.pone.0011296 
16. Ballerini C, Guerini FR, Rombolà G, Rosati E, Massacesi L, Ferrante P et al. HLA-multiple sclerosis association in continental Italy and correlation with disease prevalence in Europe. J Neuroimmunol. 2004;150(1-2):178-85. doi:10.1016/j.jneuroim.2004.01.015

17. Mack SJ, Tu B, Lazaro A, Yang R, Lancaster AK, Cao K et al. HLA-A; - B, -C, -DRB1 allele and haplotype frequencies distinguish Eastern European Americans from the general European American population. Tissue Antigens. 2009;73(1):17-32. doi:10.1111/j.1399-0039.2008.01151.x

18. Probst CM, Bompeixe EP, Pereira NF, Dalalio MM, Visentainer JE, Tsuneto LT et al. HLA polymorphism and evaluation of European, African, and Amerindian contribution to the white and mulatto population from Paraná, Brazil. Hum Biol. 2000;72(4):597-617. doi:

19. Alves-Leon SV, Papais-Alvarenga R, Magalhães M, Alvarenga M, Thuler LCS, Fernandez y Fernandez O. Ethnicity-dependent association of HLA DRB1-DQA1-DQB1 alleles in Brazilian multiple sclerosis patients. Acta Neurol Scand. 2007;115(5):306-11. doi:10.1111/j.1600-0404.2006.00750.x

20. Brum DG, Barreira AA, Louzada-Junior P, Mendes-Junior CT, Donadi EA. Association of the HLA-DRB1*15 allele group and the DRB1*1501 and DRB1*1503 alleles with multiple sclerosis in White and Mulatto samples from Brazil.J Neuroimmunol. 2007;189(1-2):118-24. doi:10.1016/j.jneuroim.2007.06.009

21. Paradela ER, Alves-Leon SV, Figueiredo AL, Pereira VC, Malfetano F, Mansur LF et al. The CIITA genetic polymorphism rs $4774{ }^{\star} \mathrm{C}$ in combination with the HLA-DRB1*15:01 allele as a putative susceptibility factor to multiple sclerosis in Brazilian females. Arq Neuropsiquiatr. 2015;73(4):283-8. doi:10.1590/0004-282X20150012

22. Cocco E, Murru R, Costa G, Kumar A, Pieroni E, Melis C et al. Interaction between HLA-DRB1-DQB1 haplotypes in Sardinian multiple sclerosis population. PLoS One. 2013;8(4):e59790. doi:10.1371/journal.pone.0059790

23. Kollaee A, Ghaffarpor M, Ghlichnia HA, Ghaffari SH, Zamani M. The influence of the HLA-DRB1 and HLA-DQB1 allele heterogeneity on disease risk and severity in Iranian patients with multiple sclerosis. Int J Immunogenet. 2012;39(5):414-22. doi:10.1111/j.1744-313X.2012.01104.X

24. Serjeantson SW, Gao X, Hawkins BR, Higgins DA, Yu YL. Novel HLA-DR2-related haplotypes in Hong Kong Chinese implicate the DQB1*0602 allele in susceptibility to multiple sclerosis. Eur J Immunogenet. 1992;19(1-2):11-9. doi:10.1111/j.1744-313X.1992.tb00043.x

25. Rojas OL, Rojas-Villarraga A, Cruz-Tapias P, Sánchez JL, Suárez-Escudero JC, Patarroyo MA et al. HLA class II polymorphism in Latin American patients with multiple sclerosis. Autoimmun Rev. 2010;9(6):407-13. doi:10.1016/j.autrev.2009.11.001
26. Patsopoulos NA, Barcellos LF, Hintzen RQ, Schaefer C, van Duijn $\mathrm{CM}$, Noble JA et al. Fine-mapping the genetic association of the major histocompatibility complex in multiple sclerosis: HLA and non-HLA effects. PLoS Genetics. 2013;9(11):e1003926. doi:10.1371/journal.pgen.1003926

27. Dekker JW, Easteal S, Jakobsen IB, Gao X, Stewart GJ, Buhler MM et al. HLA-DPB1 alleles correlate with risk for multiple sclerosis in Caucasoid and Cantonese patients lacking the high-risk DQB1*0602 allele. Tissue Antigens. 1993;41(1):31-6. doi:10.1111/j.1399-0039.1993.tb01974.x

28. Wu XM, Wang C, Zhang KN, Lin AY, Kira J, Hu GZ et al. Association of susceptibility to multiple sclerosis in Southern Han Chinese with HLA-DRB1, -DPB1 alleles and DRB1-DPB1 haplotypes: distinct from other populations. Mult Scler. 2009;15(12):1422-30. doi:10.1177/1352458509345905

29. Healy BC, Liguori M, Tran D, Chitnis T, Glanz B, Wolfish C et al. HLA B* 44: protective effects in MS susceptibility and MRI outcome measures. Neurology. 2010;75(7):634-40. doi:10.1212/WNL.0b013e3181ed9c9c

30. Instituto Brasileiro de Geografia e Estatística - IBGE. Brasil: 500 anos de povoamento. Rio de Janeiro: Centro de Documentação e Disseminação de Informações; 2007.

31. Pena SD, Di Pietro G, Fuchshuber-Moraes M, Genro JP, Hutz $\mathrm{MH}$, Kehdy FS et al. The genomic ancestry of individuals from different geographical regions of Brazil is more uniform than expected. PLoS One. 2011;6(2):e17063. doi:10.1371/journal.pone.0017063

32. Berg-Hansen P, Moen SM, Sandvik L, Harbo HF, Bakken IJ, Stoltenberg $\mathrm{C}$ et al. Prevalence of multiple sclerosis among immigrants in Norway. Mult Scler. 2015;21(6):695-702. doi:10.1177/1352458514554055

33. Bhargava P, Mowry EM. Gut microbiome and multiple sclerosis. Curr Neurol Neurosci Rep. 2014;14(10):492. doi:10.1007/s11910-014-0492-2

34. O'Gorman C, Lucas R, Taylor B. Environmental risk factors for multiple sclerosis: a review with a focus on molecular mechanisms. Int J Mol Sci. 2012;13(9):11718-52. doi:10.3390/ijms130911718

35. Pierrot-Deseilligny $\mathrm{C}$, Souberbielle JC. Contribution of vitamina $D$ insufficiency to the pathogenesis of multiple sclerosis. Ther Adv Neurol Disorder. 2013;6(2):81-116. doi:10.1177/1756285612473513 